\title{
Medical Information Retrieval for Healthcare: The Challenges
}

\author{
Irmawati S., Muh. Hidayat Cakrawijaya, E. Laxmi Lydia, K. Shankar, Phong Thanh Nguyen
}

\begin{abstract}
The Medical Information Retrieval (MIR) refers to collect datasets from research agencies, institutes, medical clinical or data from research organizations like hospitals etc and use this information for further experiments for the betterment to get new solutions for the complex health diseases. The purpose of such kind of information retrieval system is to improve the healthcare system, diagnose the disease in less time and try to provide better alternate treatment solutions to the patients. Today the internet has connected the whole world and it is very easy for the medical research organizations to exchange the medical data and exchange the test results. They are not required to do the same experiments again which has already done in any of the country. The research or healthcare research organizations can perform the next level of experiments with the help of collected medical information from the researchers of one country. Even the countries can share the medical information and they can combine do the medical experiments with the retrieved information. However in this research it is tried to study the importance of Medical Information Retrieval and its methods and it is also studied how it is useful in Healthcare. In this study it is noted that there are several challenges the research have to face. Because the different countries have different languages. The medical terms are different in different countries so that sometimes it is difficult to synchronies the retrieved information from different sources. One biggest challenge is that it is not possible to get the accuracy of the data.
\end{abstract}

Keywords : Medical Information, Information Retrieval Methods (IRM), Information for healthcare system.

\section{INTRODUCTION}

The one of the biggest issue with Medical Information Retrieval system for the researchers and the medical institutes is that they should have the proper knowledge to understand the data and should have capabilities to convert the data according to the information required for healthcare system. The Medical information retrieval is the process to improve the healthcare and get the required helpful information from the available explosive amount of available data for healthcare domain. The Medical Information Retrieval (MIR) alludes to gather datasets from research offices, establishments, therapeutic clinical or information from research associations like emergency clinics and so on and

Revised Manuscript Received on September 22, 2019

* Correspondence Author

Irmawati S., Universitas Megarezky, Indonesia.

Muh. Hidayat Cakrawijaya, Universitas Megarezky, Indonesia

E. Laxmi Lydia, Professor, Vignan's Institute of Information Technology(A), Department of Computer Science and Engineering, Visakhapatnam, Andhra Pradesh, India.

K. Shankar, Department of Computer Applications, Alagappa University, India.

Phong Thanh Nguyen*, Department of Project Management, Ho Chi Minh City Open University, Vietnam. E-mail: phong.nt@ ou.edu.vn utilize this data for further tests for the improvement to get new answers for the intricate wellbeing maladies.

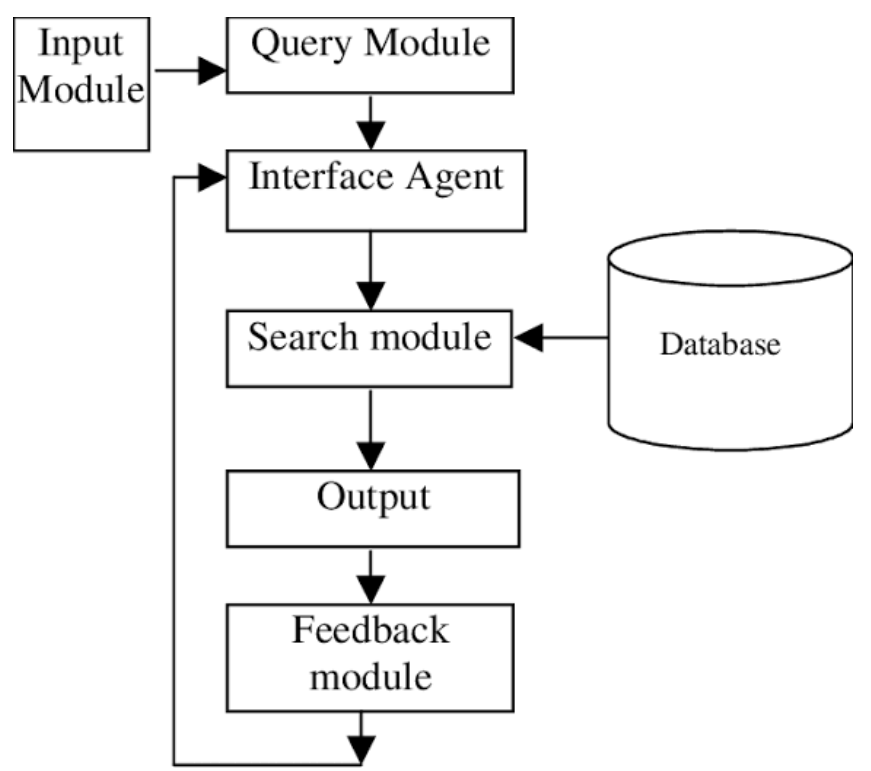

Figure 1. Medical Information Retrieval System Basis Model which acquired Agents, Clinical Data or Institutions Data and Stored in a Centralized Database.

The motivation behind such sort of data recovery framework is to improve the human services framework, analyze the infection in less time and attempt to give better substitute treatment answers for the patients. Today the web has associated the entire world and it is exceptionally simple for the therapeutic research associations to trade the medicinal information and trade the test outcomes. They are not required to do similar trials again which has just done in any of the nation. The examination or medicinal services look into associations can play out the following degree of trials with the assistance of gathered therapeutic data from the scientists of one nation. Indeed, even the nations can share the medicinal data and they can join do the therapeutic investigations with the recovered data. Anyway in this exploration it is attempted to think about the significance of Medical Information The patient data information retrieval example is shown in the figure below: 


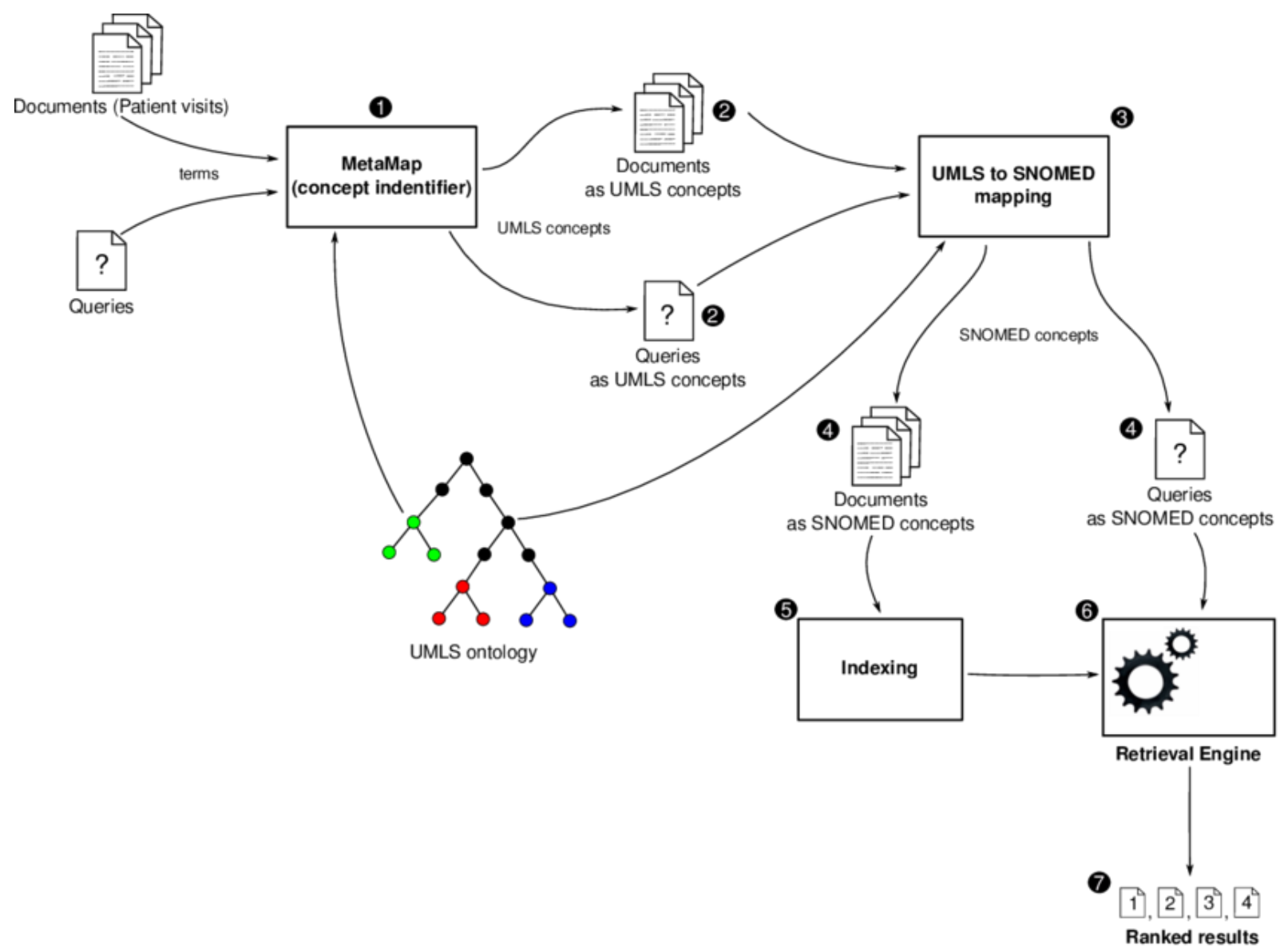

Figure 2. Example of Medical Information Retrieval System for Healthcare

Retrieval and its techniques and it is additionally considered how it is valuable in Healthcare. In this investigation it is noticed that there are a few difficulties the exploration need to confront. Since the various nations have various dialects.

\section{CHALLENGES IN INFORMATION RETRIEVAL SYSTEM FOR HEALTHCARE}

It is very important to check the authenticity of the information collected for healthcare system. Because the incorrect data may slow the process of research and even for future the serious results may seems. Even the rollback of research process is very difficult. In the figure given below it is shown that what problems the researchers may face while correcting the existing datasets.

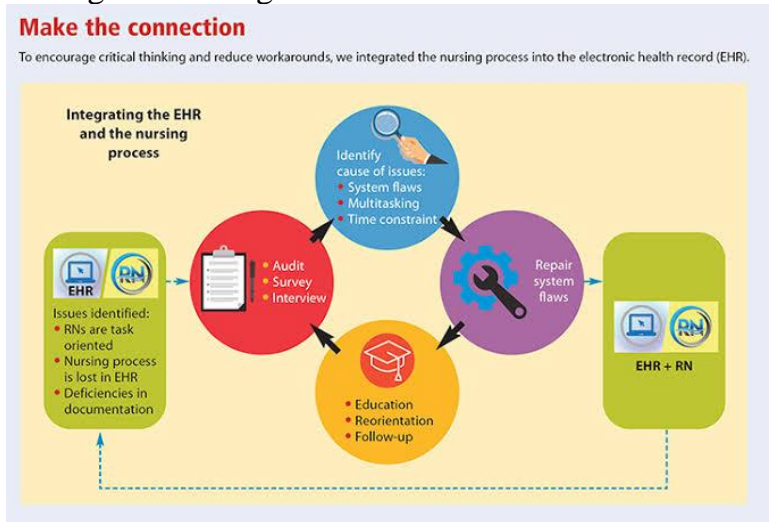

Figure 3. The challenge of Correction in the Datasets of Patient Information

Significant restorative information, for example, pathology reports, usable reports, release rundowns, and radiology reports are put away in literary structure. Databases containing free-content restorative stories regularly should be looked to discover applicable data for clinical and research purposes. The most common challenges in information retrieval for the healthcare systems are:

Table 1. Challenges in Medical Information Retrieval for Healthcare System.

\begin{tabular}{|c|c|}
\hline $\begin{array}{c}\text { Lack of } \\
\text { Knowledge }\end{array}$ & $\begin{array}{c}\text { The lack of knowledge in new } \\
\text { researchers may not understand the } \\
\text { format of the information. So that it is } \\
\text { very difficult to process such datasets } \\
\text { for further research. }\end{array}$ \\
\hline $\begin{array}{c}\text { Correction in } \\
\text { Medical } \\
\text { Information } \\
\text { Datasets }\end{array}$ & $\begin{array}{c}\text { The rollback of process or correction is } \\
\text { one of the biggest challenge as it may } \\
\text { led the waste of many months or years } \\
\text { of researches. }\end{array}$ \\
\hline $\begin{array}{c}\text { Understanding } \\
\text { of Language }\end{array}$ & $\begin{array}{c}\text { The researchers language is also the key } \\
\text { challenge in combine research with the } \\
\text { retrieved information on common } \\
\text { research for a particular disease. }\end{array}$ \\
\hline $\begin{array}{c}\text { Accuracy of } \\
\text { Information }\end{array}$ & $\begin{array}{c}\text { It is very difficult to know weather the } \\
\text { collected information is 100\% accurate } \\
\text { or not. }\end{array}$ \\
\hline
\end{tabular}

Terms that show up in these archives will in general show up in various settings. The con-content of refutation, a negative finding, is critical, since a significant number of the most much of the time portrayed discoveries are those denied by the patient or in this way "precluded." 

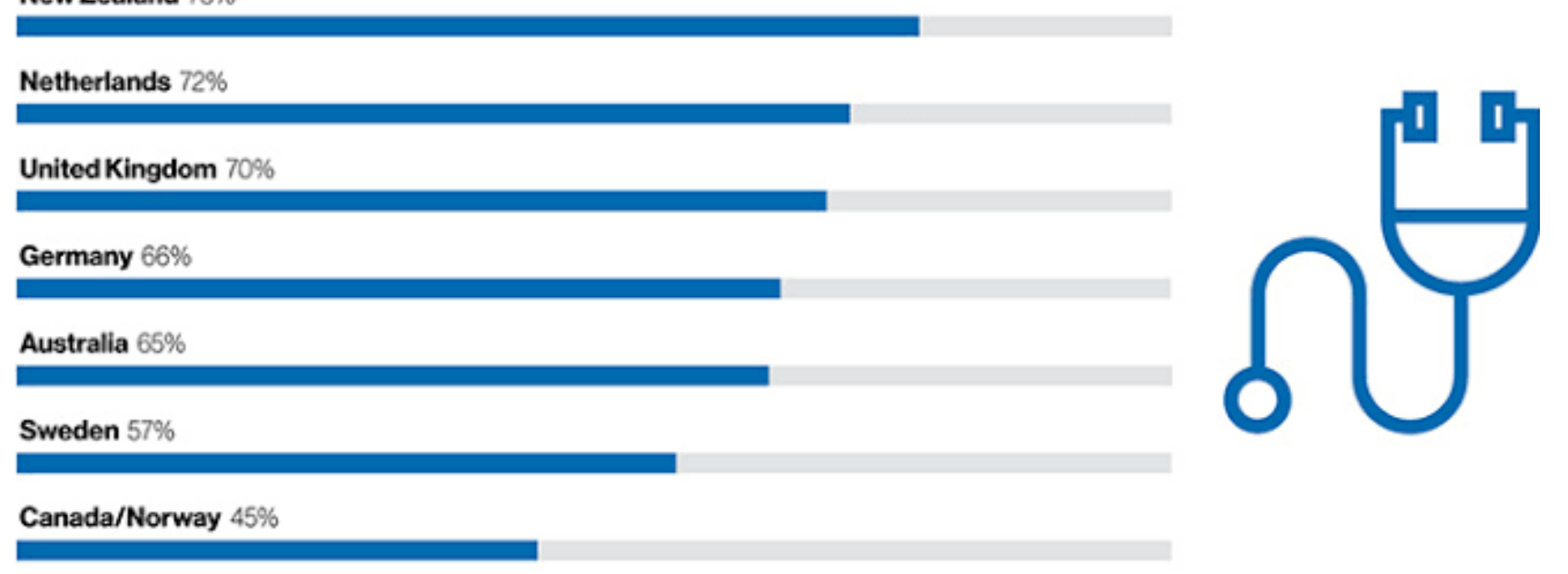

\section{Access to medical care in high-income nations varies widely, according to a recent survey.}

Figure 4. The contribution of countries wise comparison graph in Medical Information Retrieval system for healthcare

Hence, when scanning free-content stories for patients with a specific ailment, if invalidation isn't considered, a large number of the recovered records will be insignificant. The reason for this work is to build up a strategy for robotized learning of negative setting designs in restorative accounts and test the impact of setting ID on the exhibition of therapeutic data recovery. The accessible data recovery techniques help to support the procedure of analyze the sickness. Yet, in this procedure a few difficulties confronted. The one of the best issue with Medical Information Retrieval system for the examiners and the therapeutic foundations is that they should have the most ideal figuring out how to understand the data and should have abilities to change over the data as shown by the information required for social protection structure. The Medical information recuperation is the method to improve the social protection and get the essential obliging information from the available unstable proportion of open data for human administrations region. The Medical Information Retrieval (MIR) implies collect datasets from research work environments, establishments, supportive clinical or information from research affiliations like emergency focuses, and so forth and utilize this data for further tests for the improvement to get new reactions for the mind boggling thriving ailments.

The motivation driving such sort of data recovery structure is to improve the human organizations framework, explore the tainting in less time and try to offer better substitute treatment reactions for the patients. Today the web has related the entire world and it is remarkably clear for the remedial research relationship to trade the restorative information and trade the test outcomes. They are not required to do tantamount starters again which has as of late done in any of the nation.
HEALTH INFORMATION EXCHANGE (HIE) BENEFITS AND CHALLENGES

HOW DO LT/PACS USE HIE?

- Improve workflow to prepare for new patient/change-in-patient conditions

- Query patient data immediately (even in patient's home on iPads) vs, waiting for faxes or calling hospitals for information

w Ability to alter care plans based on patient information found in the HIE, such as before a home health visit

THE CHALLENGES:

- Getting all hospitals connected that LT/PACs need data from

- Patients aren't always identified as LT/PAC patients, so delivery of results to a

specific inbox or medical record is a challenge

- Community Health Record, available via secure Web portal, is an effective means of getting the data to these providers

Source: CORHIO, as part of a presentation at the Office of the National Coordinator for Health Information Technology annual meeting, Feb. 3, 2015

Figure 5. The Medical Healthcare Benefits and Challenges

The evaluation or therapeutic organizations explore affiliations can play out the going with level of primers with the assistance of amassed healing data from the analysts of one nation. Without a doubt, even the nations can share the helpful data and they can join do the medicinal assessments with the recovered data. Regardless in this examination it is attempted to think about the significance of Medical Information Retrieval and its frameworks and it is likewise seen as how it is noteworthy in Healthcare. In this assessment it is seen that there are several issues the examination need to face. Since the various nations have various tongues. The remedial terms are indisputable in various nations so now and again it is hard to synchronies the recovered data from various sources. One greatest test is that it is past the area of inventive personality to would like to get the exactness of the information. For such information recuperation system there are many audit associations or associations are available who assemble information by web structures, online interfaces,

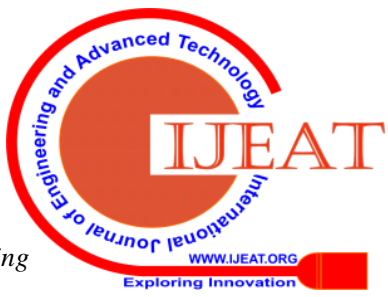


clinical or inquire about foundation data and method them in a precise way. The calculation exhibited essentially improves the presentation of data recovery done on restorative accounts. The accuracy im-demonstrates from about $62 \%$, when utilizing setting uncaring recovery, to almost $100 \%$. The effect on review is just minor. What's more, setting touchy inquiries empower the client to scan for terms in manners not generally accessible.

The therapeutic terms are distinctive in various nations so that occasionally it is hard to synchronies the recovered data from various sources. One greatest test is that it is beyond the realm of imagination to expect to get the exactness of the information. For such information retrieval system there are many survey agencies or companies are available who collect information by web forms, web portals, clinical or research institute data and process them in a systematic way.

\section{DATA AND RESEARCH ORGANIZATION DECISION}

Healthcare administrations research will add to the improvement of medicinal informatics and the utilization of electronic interchanges media in the wellbeing field. As supplier and authorizing associations keep on making huge interests in restorative data frameworks, specialized advances will give wellbeing administrations scientists and administrators access to new data sets; these, thus, offer chances to grow new show models and situations and to devise commonsense and moral approaches to incorporate information from long haul care, inpatient, mobile, and different settings for examinations of value, cost, and access. Moreover, informatics and a developing national data framework - including suppliers, buyers, buyers, and payers - could improve decisionmaking forms (for example, about issues that include costs, cost-adequacy, and morals).

\section{CONCLUSION}

The available information retrieval methods help to boost the process of diagnose the disease. But in this process several challenges faced. The one of the greatest issue with Medical Information Retrieval framework for the analysts and the medicinal establishments is that they ought to have the best possible learning to comprehend the information and ought to have capacities to change over the information as indicated by the data required for social insurance framework. The Medical data recovery is the procedure to improve the social insurance and get the necessary accommodating data from the accessible touchy measure of accessible information for human services area. The Medical Information Retrieval (MIR) insinuates assemble datasets from research workplaces, foundations, helpful clinical or data from research affiliations like crisis centers, etc and use this information for further tests for the improvement to get new responses for the complex prosperity diseases.

The inspiration driving such kind of information recuperation structure is to improve the human administrations system, investigate the contamination in less time and endeavor to offer better substitute treatment responses for the patients. Today the web has related the whole world and it is uncommonly straightforward for the restorative research relationship to exchange the therapeutic data and exchange the test results. They are not required to do comparable preliminaries again which has quite recently done in any of the country. The assessment or restorative administrations investigate affiliations can play out the accompanying level of preliminaries with the help of assembled remedial information from the researchers of one country. Undoubtedly, even the countries can share the restorative information and they can join do the remedial examinations with the recuperated information. In any case in this investigation it is endeavored to consider the importance of Medical Information Retrieval and its systems and it is also viewed as how it is significant in Healthcare. In this examination it is seen that there are a couple of troubles the investigation need to stand up to. Since the different countries have different tongues. The restorative terms are unmistakable in different countries so that every so often it is difficult to synchronies the recouped information from different sources. One biggest test is that it is past the domain of creative mind to hope to get the precision of the data. For such data recovery framework there are many review organizations or organizations are accessible who gather data by web structures, online interfaces, clinical or research establishment information and procedure them in an orderly manner..

\section{REFERENCES}

1. Simpao A.F., Ahumada L.M., Gálvez J.A., Rehman M.A. A review of analytics and clinical informatics in health care. J. Med. Syst. 2014;38:45. doi: 10.1007/s10916-014-0045-x.

2. A. McAfee, E. Brynjolfsson, T. H. Davenport, D. J. Patil, \& D. Barton (2015), "Big data: the management revolution," Harvard Business Review, vol. 90 , no. 10 , pp. 60-68.

3. C. Lynch (2008), "Big data: how do your data grow?" Nature, vol. 455 , no. 7209 , pp. 28-29.

4. A. Jacobs (2009), "The pathologies of big data," Communications of the ACM, vol. 52, no. 8, pp. 36-44,

5. Yang C, Li C, Wang Q, Chung D \& Zhao H(2015). "Implications of pleiotropy: challenges and opportunities for mining big data in biomedicine". Front Genet. 2015, vol.6, issue.229.

6. Moher D., Liberati A., Tetzlaff J., Altman D.G., Group P. Preferred reporting items for systematic reviews and meta-analyses: The PRISMA statement.

7. Tomar D., Agarwal S. A survey on Data Mining approaches for Healthcare. Int. J. Bio-Sci. Bio-Technol. 2013.

8. Bellazzi R., Ferrazzi F., Sacchi L. Predictive data mining in clinical medicine: A focus on selected methods and applications. WIRE. 2011;1:416-430. doi: 10.1002/widm.23.

9. Sigurdardottir A.K., Jonsdottir H., Benediktsson R. Outcomes of educational interventions in type 2 diabetes: WEKA data-mining analysis. Patient Educ. Couns. 2007;67:21-31.

10. Jimeng Sun \& Chandan K. Reddy, "Big Data Analytics for Healthcare". https://archive.siam.org/meetings/sdm13/sun.pdf

11. Powell, James E. (2014), "Q\&A: Advanced data visualization: from atomic data to big data."

12. Ledbetter, Craig S. \& Morgan, Matthew W.(2001), "Toward best practice: leveraging the electronic patient record as a clinical data warehouse". Journal of Healthcare Information Management, vol.15, issue.2, pp.119-131.

13. Lakshman, A. \& Malik, P.(2010), "Cassandra: a decentralized structured storage system", Operating Systems Review, vol.44, issue.2, pp.35-40.

14. Raja, U., Mitchell, T., Day, T. \& Michael Hardin, J. (2014). "Text mining in healthcare. Applications and opportunities".

15. Raghupathi W., Raghupathi V. Big data analytics in healthcare Promise and potential. Health Inf. Sci. Syst. 2014;2:3 